\title{
Differences in teaching female and male intimate examinations: A qualitative study
}

Jenny Gleisner and Karin Siwe

The self-archived postprint version of this journal article is available at Linköping University Institutional Repository (DiVA):

http://urn.kb.se/resolve?urn=urn:nbn:se:liu:diva-164910

N.B.: When citing this work, cite the original publication.

Gleisner, J., Siwe, K., (2020), Differences in teaching female and male intimate examinations: A qualitative study, Medical Education, 54(4), 348-355. https://doi.org/10.1111/medu.14126

Original publication available at:

https://doi.org/10.1111/medu.14126

Copyright: Wiley (12 months)

http://eu.wiley.com/WileyCDA/ 
DR. JENNY GLEISNER (Orcid ID : 0000-0003-4318-0593)

Article type : Original Research

\title{
Differences in teaching female and male intimate examinations.
} A qualitative study

\author{
Jenny Gleisner ${ }^{a *}$ and Karin Siwe ${ }^{b}$
}

${ }^{a}$ Research Fellow at the Department of Thematic Studies - Technology and Social Change, Linköping University, Linköping, Sweden; ${ }^{b}$ Senior Consultant (MD, PhD) at the Department of Obstetrics and Gynaecology, and the Department of Clinical and Experimental Medicine,

Linköping University, Linköping, Sweden

e-mail for the *corresponding author: jenny.gleisner@liu.se

\section{NOTES ON CONTRIBUTORS:}

Jenny Gleisner is a Research Fellow at the Department of Thematic Studies, the unit of Technology and Social Change, at Linköping University, Sweden. She has a background in Science and Technology Studies and Social Anthropology. Her ethnographic studies include exploring knowledge practices, norms and emotions in medical professions and in medical education.

Karin Siwe is Senior Consultant at the Department of Obstetrics and Gynaecology, and the Department of Clinical and Experimental Medicine, Linköping University, Linköping, Sweden. Her research concerns

This article has been accepted for publication and undergone full peer review but has not been through the copyediting, typesetting, pagination and proofreading process, which may lead to differences between this version and the Version of Record. Please cite this article as doi: 10.1111/MEDU.14126

This article is protected by copyright. All rights reserved 
learning in higher education, development of clinical skills, and the use of professional patients/Gynaecological Teaching Associates.

AUTHOR'S NOTE: We are most grateful to students and doctors who shared their time and experiences with us. This work was supported by the Swedish Research Council (DNR 2013-8048). Correspondence concerning this article should be addressed to Jenny Gleisner, Department of Thematic Studies Technology and Social Change, Linköping University, 58183 Linköping, Sweden, jenny.gleisner@liu.se.

\section{ORCID}

Jenny Gleisner (iD http://orcid.org/0000-0003-4318-0593

Karin Siwe (iD https://orcid.org/ 0000-0002-5235-7824

\section{ABSTRACT}

Objectives: Teaching intimate examinations to medical students has been recognized as difficult because of the anxious feelings that the students may experience. For their professional development, previously incorporated understandings need to be relearned: how to transgress boundaries that regulate intimacy and physical closeness, learning to examine and touch other peoples' bodies, and talking about things that are otherwise taboo. This paper compares how students learn to perform two intimate examinations - the digital rectal exam of the prostate (DRE) and the bimanual pelvic exam (PE) - and analyses how norms and expectations affect how students learn to approach them.

Methods: This study is based on ethnographic work: in-depth qualitative interviews with two urologists and nine medical students in semesters 4,8 and 11 of a medical education programme in Sweden, observations of three learning sessions where 16 students performed the PE on professional patients, and two days of observations at a urology out-patient clinic.

Results: The educational approach to the PE and DRE differ. The PE is taught as sensitive and to be handled with care, using a well-documented learning concept including interpersonal and technical skills. The patient's exposed position in the gynaecological chair, possible previous negative experiences of PE or sexual exploitation are taken into account. In contrast, there is no 
educational concept for teaching the DRE. The students perform their first DRE on a clinical patient. The DRE is also handled with care, but with less sensitivity. The patients' possible previous negative experiences are not discussed and are thus made invisible.

Conclusions: Well-established routines in performing the PE help doctors and students to be attentive to patients' emotions and previous experiences, and remind them to perceive the examination as sensitive. Aligning the teaching of the DRE with that of the PE will improve how the male prostate patient is approached.

Keywords: Gynaecolocal Teaching Associates/GTA, professional patients, learning, medical education, professional approach, pelvic examination, digital rectal examination, prostate 


\section{INTRODUCTION}

Learning a professional approach is part of becoming a doctor. This includes what Stuart Shapiro calls learning the "standards of practice" of how to carry out the work, and how to handle patient meetings professionally. ${ }^{1}$ Evoking and shaping the expected feelings of the professional role is defined by the sociologist Arlie Russel Hochschild as emotion management. ${ }^{2}$ Medical students are socialized into the profession as they learn a common, shared approach, ${ }^{3}$ and how to work $a$ s a doctor. Through this situated learning, ${ }^{4}$ students are expected to comply with emotion norms and acquire the "proper feelings" of the medical profession. ${ }^{5}$ From this perspective, emotions and feelings are used as interconnected concepts including both what a person experiences and what s/he expresses. ${ }^{67}$ Hence, previously incorporated understandings need to be relearned: how to transgress boundaries that regulate intimacy and physical closeness, learning to examine and touch other peoples' bodies, and talking about things that are otherwise taboo. ${ }^{8} 9$

Studies of medical students learning to do genital and rectal examinations show that these exams cause anxiety among students ${ }^{10} 11$ and that the students benefit from adequate training ${ }^{12}$ and working with simulations, ${ }^{13}$ as these provide immediate feedback to students on their technique and communication skills. ${ }^{14}$ Teaching intimate examinations to medical students has been recognized as difficult because of the anxious feelings that the students may experience, which also affects the patients' experiences. ${ }^{15}$ Not enough work has been done to explore what a professional approach entails and how it is developed through medical school. ${ }^{16} 17$ More research is needed that analyses how students are taught to handle emotions (their own as well as the patients') as part of professional development, and especially research that focuses on the way norms and expectations in relation to gender aspects shape different doctor-patient encounters. ${ }^{18}$

The digital rectal examination of the prostate (DRE) and the pelvic examination (PE) have a lot in common; both are gendered and intimate. But while the DRE rarely is spoken of as sensitive, ${ }^{19}$ it has become a self-evident truth in the medical literature that the PE is a physically intimate exam which should be performed and taught with particular concern and respect for the patient's feelings and any previous experiences she may have. ${ }^{20}$ Further, special attention must be given to her experiences of being seated in a gynaecological chair because of its exposed position. ${ }^{21}$

All of the aspects which allegedly make the PE so unique can also be applied to the DRE. The DRE is also an exam where the patient removes the clothes from the lower part of the body and 
exposes body parts that are otherwise only shown in very private contexts. It relates to sexuality and pleasure in several different ways, since prostate problems per se, or the treatment for these, can affect a patient's sexual abilities and practices. Furthermore, the patient's bodily position can be associated with sexual positions, or with being exposed, which both make it sensitive.

Comparing and contrasting these two intimate examinations serve as examples to discuss how teaching methods impact student learning and students' professional development.

The aim of this paper is to analyse how norms and expectations affect how medical students learn a professional approach by exploring how intimate examinations like the PE and the DRE are taught in medical education, and if the male prostate patient and the female gynaecology patient are approached in different ways.

\section{METHODS}

\section{Context}

This study was carried out in Sweden where medical education programmes last 5.5 years. The first five semesters include preclinical studies, where theory-based lectures and seminars are alternated with communication and some skills training. The following semesters include also clinical rotations.

This medical education programme uses the teaching method of problem-based learning, ${ }^{22}$ and the students in this study were continuously involved in group-based activities, sharing experiences as part of their joint learning. Discussing how different scenarios could, and should, be handled in a professional way, emphasizing not only, for example, diagnosis and treatment but also how to encounter patients "in a proper way" is part of the learning goals. ${ }^{23}$ Hence, the students were used to reflect upon their experiences of being medical students as well as to openly share and discuss how they react emotionally in different situations and how they believe these feelings need to be managed to become a "good doctor".

\section{Ethnographic work: observations and interviews}


This study was carried out through ethnographic work. Ethnography as a research method brings valuable insights into the participants' social setting, ${ }^{24}$ and analyses the often taken-for-granted, in this case how the concern for patients' experiences, or the lack of them, affects how intimate examinations are taught differently in medical education. One of the benefits of studying norms and emotions in healthcare through students is that how to handle different kind of situations "as a doctor" has not yet become self-evident, internalized or invisible to the students, and therefore it is easier to see, articulate and discuss. As a method, ethnography makes it possible to study what people do and how they do it. Shorter observations, such as the ones this study entails, bring insights to the students' learning situations. Findings from the observations were further explored during interviews as this is also a way to validate findings and interpretations with the interviewees.

To present research with an ethnographic approach means to show not only what was said or done, but also in which context. ${ }^{25}$ Capturing the nuances of how and with which emotions something is said, e.g. nervously, worriedly or excitedly, i.e. what Michalinos Zembylas calls "nondiscursive practices", ${ }^{26}$ is of significant importance when studying emotions and learning a professional approach. In this study, field notes from observations and transcriptions of audited interviews include not only what was said or done, but also interpretations and descriptions. This ethnographic sensibility is part of how the empirics are presented in this paper, aspiring to give rich descriptions. ${ }^{27}$

\section{Data collection and analysis}

The first author (JG), who is well experienced in ethnographic methods and doing qualitative research in medical- and educational settings, carried out the empirical work. This includes observation of learning sessions (LS) with professional patients (PP), also called Gynaecological Teaching Associates (GTA), observations at a urology out-patient clinic, and interviews with medical students and urologists.

Three LS were observed: two with students in semester 4 (bimanual PE), and one with students in semester 11 (speculum and bimanual PE), where a total of sixteen students (nine women and seven men, from 20 to 41 years old) performed the PE. During observations of LS, JG focused on 
observing what occurred in the room and how the students, the PPs and the teaching gynaecologist (if present in the room) interacted with each other and with different material objects in the room, such as the gynaecological chair and other equipment. Observations were documented through field notes which were later rewritten into rich descriptions.

This way of collecting and working with field notes was also applied during observations at the urology clinic. For two days, JG followed a female urologist's work, where the latter met prostate patients at a urology out-patient clinic. The aim was to gain insight into the urologist's day-to-day work, and how the patient encounters and examinations are carried out. During one of these days the urologist also supervised an $8^{\text {th }}$ semester student.

In addition, JG conducted hour-long in-depth interviews with nine medical students (seven women and two men, from 23 to 41 years old) and two urologists (one man and one woman, the latter was also observed). Five of these students participated in the observed LS (two students from semester 4 and three students from semester 11). The other four students, in semester 8 , were recruited during their clinical training in surgery/urology. The interview questions concerned the doctors' and students' experiences of learning to carry out intimate examinations, and their thoughts on how these are taught and learned.

All material from observations and interviews was coded and thereafter thematised. The examples presented in this paper reflects on that process, illustrating aspects of learning a professional approach and managing emotions, conducting intimate examinations, how to encounter patient bodies, and interaction with the material setting. ${ }^{28}$

As the study was done in Sweden, all quotes and excerpts from field notes and interviews have been translated into English by JG, and subsequently edited by an English language service to achieve the correct nuances and meanings in the translations. The language in the quotations has been edited, but without altering the meaning of the sentences.

The second author $(\mathrm{KS})$ teaches in the medical education programme where the study took place and is also well experienced in doing qualitative research. She facilitated access to the field, but did not partake in interviews and was not given information on which students were interviewed. The purpose of this was to minimize the students' being affected by a teacher's presence. KS was 
invited into the analytical process when excerpts from field notes and quotes from interviews had been transcribed into text.

\section{Ethical considerations}

This project has followed the ethical guidelines of The Swedish Research Council for research with professionals about their profession or the learning of that profession. ${ }^{29}$ It took place within the context of a larger sociological study on the impacts of prostatectomy that received ethics approval from the Research Ethics Board at the Medical Faculty, Linköping University. The additional data collection required of this study was deemed exempt from further review by the same Board. Nonetheless, a written approval from the director of the medical programme was procured, all participants were asked for their informed consent, and no identifying information about patients was collected.

\section{FINDINGS}

Medical students in this education programme are introduced to the DRE of the prostate and the $\mathrm{PE}$ in very different ways. The university has a well-documented concept for learning the PE. ${ }^{30} \mathrm{~A}$ lecture is given by a gynaecologist on interpersonal and technical skills during semester 4, and an instructional video is shown. ${ }^{31}$ Students then participate in two learning sessions (LS) with professional patients (PP). Students perform a bimanual palpation of the uterus during semester 4, and a complete PE with instruments and palpation of uterus and adnexa during semester 11, prior to the clinical rotation in obstetrics/gynaecology. The PE is one of the first examinations that the students get to carry out. During the fourth semester, students are still in the preclinical phase and have so far extensively trained communication skills with patients but only performed some physical examinations, such as auscultation of the heart and lungs, examining joints and peripheral circulation and measuring blood pressure. Practicing the PE early in medical training is considered to cause less anxiety among students and thus create a better leaning situation. Practising performing a digital rectal examination of the prostate is part of the student's clinical training during the fourth year, when they shadow medical doctors specialized in urology. The students do 
not attend any theoretical or practical preparations dedicated to this exam, as this is not included in the curriculum.

The following section starts by looking more closely at how the DRE is taught and contrasting it with the PE.

\section{The digital rectal exam of the prostate}

At the urology clinic where this study took place, the doctor and the patient are usually alone in the examination room. A nurse meets and greets the patient in the waiting room and shows him to the examination room. If tests are to be conducted, for example measuring the flow rate of the patient's urine, this is performed by a urology nurse who gives the results to the urologist prior to meeting the patient. If a biopsy is to be taken, a nurse is summoned, who enters the room, assists during the procedure and leaves.

Describing the prostate exam in this straightforward way presents an image of the DRE as a rather non-sensitive, unemotional examination, both for the patient and for the person performing it, which also reflects on how it is taught to students. But behind this description lies hidden a multitude of aspects which are not at all self-evident, nor as simple as they seem, such as the examination position, what is examined and why, and questions about sexuality and intimacy.

The students interviewed had neither theoretical knowledge of the procedure of performing the DRE, nor of how patients might experience the examination. The course literature on the topic explains only briefly that the prostate is examined through the anal opening and that the examination is meant to estimate the prostate's size, form, shape and texture. It also describes the prostate exam as "one of the more intrusive examinations" and that men "experience it as very uncomfortable and unpleasant". ${ }^{32}$ The students reflected that the latter was never expanded upon, and they were not given advice on how to deal with the situation prior to their first clinical experience of meeting a patient. When it was time for them to examine, they were simply encouraged to do it. One of the students said:

The doctor just asked me "Have you done a prostate examination before?" I said, “No I haven't, and I don't know how it's done". "Well good”, the doctor said, “you 
can practice now”. When I asked, "Well okay, but shouldn't I see one first before I try?" she responded: "No, you won't see anything, just insert your finger and I'll tell you what to look for". (Student A, 31 years old, man, semester 8)

Another student said:

It was at the beginning of this semester and I was asked to do it. But if you don't have the theoretical knowledge, you don't really know what you're looking for. (Student B, 23 years old, man, semester 8)

During clinical training, both the student and the doctor usually perform the DRE, given that the patient agrees to the student participating. The students were not taught how to encounter the male prostate patient in any specific way, but this does not mean that there are not any. The following example from the urology clinic illustrates what the urologist said and did when beginning the examination.

The urologist has put on gloves and applied lubricant to her right index finger. "Now I'm going to start the examination" she says to the patient, who is lying on his side on the examination table. He has his back towards her, knees pulled up to his chest and pants drawn down around his ankles. The urologist puts one hand on the patient's hip, and then slowly inserts the other hand's index finger into the patient's anus to feel his prostate. (excerpt from field notes)

The urologists interviewed for this study explained quite thoroughly how they have developed their own routines for performing the DRE, for example, how to explain the examination to the patient, to look away when the patient undresses, and how, as the excerpt shows, to put a hand somewhere else on the patient's body before starting to examine. But routines of how to handle the patient encounter were not articulated to the students.

As shown, teaching the DRE mainly focused on the exam, not on how to talk to the patient. When asked, the interviewed doctors and students said that a patient's sex life is usually discussed in relation to how a prostate problem or treatment can affect a patient's sex life, but not regarding the patient's prior experiences. 


\section{The pelvic examination}

Learning to perform the PE is done in a completely different way and context than the DRE. The students are actively prepared before they perform the first PE on a PP. The PPs are women who are recruited by midwives and gynaecologists to, together with a gynaecologist, teach the exam. Hence, the PP, upon whom the students practise their exams, are both instructors and patients. They guide the students through the process, explaining how and when they should observe the external genitals, and how to use their hands and fingers when examining the internal reproductive organs. Just as with the DRE, one cannot see how the examiner moves his/her fingers inside the patient body, but the PP helps him or her to locate and interpret what he or she is touching and feeling.

The preparatory lecture and the learning sessions with PPs address patients' possible feelings about the exam, as well as feelings the students might have about the exam as such and about becoming a novice examiner. The following excerpt depicts a situation where a group of students in semester 4, two PPs and JG were sitting in the waiting room of the gynaecological clinic.

The teaching gynaecologist is the last person to join the group in the waiting room, and the only one wearing scrubs. She pulls out a chair, sits down and greets us all. She explains today's learning session and asks the students: "Is it correct that you've only listened to hearts and lungs so far?" The students confirm that they have no other experience of examining patients. Everyone, including the two professional patients, is asked to introduce themselves and to state their expectations. All but one of the students say that they are nervous. The gynaecologist tells them that it is normal to be nervous and that it would be strange if they were not. The one student who said that he was not nervous explains that he is a trained nurse and has inserted catheters and therefore is not uneasy with the situation. When he says this, the gynaecologist looks at him and says that she has heard others say that too, but that this is usually experienced as something different. She continues, saying that when inserting a catheter, you are still on the outside of the body, but when doing the pelvic examination, you are entering the vagina. "That's a lot of boundaries to cross", she concludes. (excerpt from field notes) 
The excerpt shows how the teaching gynaecologist framed this exam as something different from other medical procedures, acknowledging that it might be an emotionally laden and a sensitive situation, for the medical students as well as the patients. Students learned that it is important that they meet and greet the patient in the waiting room, in order to establish contact and trust. This is in contrast to the DRE, where a nurse brings the patient to the examination room. At the simulated practice session, the students also learn that they should look away while the patient is undressing and how they should express themselves when talking to the patient. The students were taught to be attentive to any potential prior experiences that the patient may have had which could affect how the patient experiences the examination situation. These "prior experiences" could be, for example, sexual abuse or previous negative experiences of being examined. The routines taught during these learning sessions acknowledge the patient's feelings, while also helping the inexperienced medical student to handle his or her own feelings.

\section{Intimate and exposed examining situations}

The DRE and the PE are intimate examinations, but are not given the same attention at the medical school where this study was conducted. This section will explore further the similarities and differences between the examinations, by focusing on the sensitivity of the examinations.

Sensitivity refers mainly to two aspects: that a private and intimate part of the body is being examined, and the position in which the patient body is examined.

Students spoke of their own reactions to the female patient's naked body, of looking at it, but also in relation to approaching and examining the body - thus, in line with how the examination was framed by the teaching gynaecologist earlier. One of the students said the following about the first learning session with PP:

When she [the professional patient] placed herself in the chair, I thought to myself “Gosh, she’s really naked”. (Student E, 26 years old, woman, semester 4)

Students interviewed described bodily intimacy during the PE in the following ways:

That part of the body is usually about pleasure and sexuality, and now someone is supposed to examine it from a medical perspective. That is a completely different 
situation. It is also a very private part of the body. You don't show it to anyone at any time or anywhere. And suddenly you're expected to do that, to let someone look and touch... I mean, touching the inside of the vagina isn't even something you do yourself. (Student C, 24 years old, woman, semester 8)

Another student said:

It's a very private area of the body, not something other people normally see. In comparison, listening to someone's heart isn't strange because you can take your shirt off at the beach or by the pool. But to examine the genitals and to ask questions about a person's sexual habits or vaginal discharge... These questions are part of the examination. But it is usually not something you talk about. (Student D, 41 years old, woman, semester 11)

In contrast to the PE, students articulated that the DRE was still an exam for which the patients are willing and ready to undergo, even if it may be uncomfortable and unpleasant. One medical student explained it like this:

When the patient decides that he wants to see me, he expects me to come really close, and that I will examine him as intimately as I can. That's what he expects from me. (Student F, 25 years old, woman, semester 11)

In light of observations of medical students practicing PEs, this explanation led to many more questions. Neither the female patient nor the PE was spoken of in this way, even though it is selfevident that also patients who seek help from a gynaecologist are aware that they will be examined.

The complexity of performing intimate examinations increases when focusing on the examining positions. During the learning sessions with PP, one of the things students practise is how to deal with the patient's exposed position when seated in the gynaecological chair. The examination chair dictates the physical position of the patient's body. It places the patient in a half-sitting position, with her legs in stirrups. The options for adapting the chair to the person being examined are limited. The chair is shaped in such a way as to create a good, ergonomically comfortable position for the doctor. 
The patient's position during the DRE is not as self-evident, and different doctors choose different positions for the exam. When the urologists and the medical students were asked why they chose a particular position, there was a discursive shift in how they spoke about the DRE. It changed from describing the situation as rather unproblematic to being attentive to how patients may experience different positions. However, no one mentioned that a male patient may have previous experiences similar to those of the female patient.

Most of the interviewees explained that they asked the patient to lie on his side, with his trousers pulled down and his knees up towards his chest. This was described as the least uncomfortable or exposed position for the patient. One of the students explained:

I watched a young man who had an inflamed prostate being examined in a standing position, leaning forward, and he looked so uncomfortable. I thought, no, that is not how I want to do it. (Student G, 25 years old, woman, semester 11)

One of the urologists and one of the final-year students preferred to examine their patients in the standing position from behind. They described in detail how they explained the benefits of this position to their patients, that it was about creating the best possible conditions for them to examine the prostate. No one mentioned having the patient on their knees and elbows on the examination table, and this position was discouraged in the course literature, since "many patients experience this position as both unpleasant and exposed", even though it is thought to be the "best" position for examining the prostate. ${ }^{33}$ The fact that there is no equivalent to the gynaecological chair in urology makes these discussions and negotiations about the examination position possible, allowing for consideration of both the doctor's ability to conduct the best exam and of how the patient experiences it. That the "best" position for conducting the exam is not recommended shows just how sensitive this examination is.

\section{DISCUSSION}

Using ethnographic methods, observing and interviewing to explore how intimate examinations are taught at a medical school makes it possible to study how a professional approach is taught in practice, and in specific situations. As students go through medical school, they are socialized into the profession and relearn previously incorporated understandings of how to relate to other 
people's bodies, and learn to be more caring. ${ }^{34}$ Learning the "proper feelings" of a profession, i.e. which feelings are considered "right" in different situations, is not mainly about suppressing or masking one's feelings, but about learning to understand the work of, in this case, a medical doctor. This claim builds on the work of Hochschild ${ }^{35}$ and emphasizes the collective and social aspects of professional development.

The private and invasive aspects of intimate examinations emphasize the importance of medical students learning to approach them in a professional and caring way, acknowledging the situation as potentially sensitive for the patient.

The DRE and the PE have a great deal in common. Both are intimate physical examinations, and both address questions about sexuality that are often considered taboo. However, as illustrated by empirical examples from a medical school in Sweden, they are taught and conceptualized in different ways, which shapes how students learn to handle the patient encounters.

When comparing the DRE with the PE, the lack of articulated routines for teaching the DRE becomes apparent. At the same time, we also see the benefits that routines can bring through looking at how the PE is taught. The theoretical preparations and the well-conceived learning concept applied at this medical programme with the use PPs, teach students how to perform the exam step-by-step while upholding a professional approach and caring for the patient's feelings. ${ }^{36}$ The students in this study narrated how the lack of practical and theoretical preparations affected their experiences of learning to perform the DRE. The urologists interviewed had worked out their own routines for performing the DRE, for example, to put one hand on the patient's hip before beginning the exam, in order to establish physical contact before inserting the finger, and turning away while the patient undressed. Hence, similar to how students were taught to handle the PE. But it was not systematically taught to the students.

But the question remains: why are there no articulated routines for how a DRE should be performed? Why is the DRE not handled the same way as the PE? And why is the PE treated as a much more sensitive exam in this medical programme?

We suggest that the differences in how the examinations are taught in medical education can be explained in terms of norms regarding male and female patient bodies. The importance to 
emphasize this becomes clear when studying more closely what it is that makes these two examinations intimate and sensitive.

The PE is expected to arouse negative feelings: shame, embarrassment and exposure. ${ }^{37}$ The DRE triggers a different image, one that makes invisible the men's experiences and feelings. ${ }^{38} \mathrm{~A}$ man may have experienced negative emotions similar to those of the gynaecology patient. However, this is not considered a factor that could make the exam difficult and is not brought to the attention of the students. This is in contrast to the PE, where students are continuously reminded to be aware of the women's possible experience of being exploited or abused ${ }^{39}$, as well acknowledging the possible feelings of being exposed when positioned in the gynaecological chair. In comparison, that men may find the DRE unpleasant was evident in how they reacted during the observed patient meetings, but also in how the urologists and students spoke about the different examination positions, and in how it was described in the course literature. ${ }^{40}$ The idea that a male prostate patient could have traumatic memories of, for example, sexual abuse, or previous negative experiences of being examined, is not acknowledged in the same way as it is with the woman having a PE. Hence, these differences reinforce stereotypical perceptions of men's and women's emotional experiences. ${ }^{41}$

Because there are no articulated routines for the DRE which remind the medical students that this can be a sensitive situation for the patient, there is a risk that the male patient is assumed to be unsensitive. The consequences of this are that students are not prepared to handle the encounter with the male prostate patient.

These gendered aspects are of importance for exploring when and how male and female patients are approached in different ways, and the impact of these on teaching intimate examination to medical students.

\section{Implications for medical education}

Understanding how and why a patient may find a certain examination sensitive will help the doctor to manage it appropriately. Hence it is important that medical students are prepared and learn routines for interacting with patients. These include how to respect such concerns in relation to intimate examinations as the PE and the DRE. 
Aligning the teaching of the DRE with that of the PE will improve how the male prostate patient is dealt with in medical examinations. ${ }^{42}$ Well-established routines in doing the PE help doctors and students to be attentive to patients' emotions and previous experiences, and remind them to understand and approach the examination as sensitive.

Well-established routines can also, in how the PE is described here, help a doctor or a student to handle feelings in an exam situation, both their own and those of the patient. They can also create a sense of security, both for the doctor/student and the patient.

Routines can also remind an experienced doctor who has already learned how to conduct an intimate exam like the PE or the DRE, that this can be a sensitive situation for the patient. Consequently, they can help the doctor to deal with the patient meeting in a gentle manner, acknowledging both the exposed examining position and previous negative experiences that the patient may have. Developing the curriculum in line with this would improve how students are expected to practice the DRE and how students are socialized into the profession. ${ }^{43}{ }^{44}$ Greater awareness of the DRE as a potentially sensitive examination is also important to the patients, as it helps to highlight and change norms that affect how men are encountered in healthcare.

Contributors: All authors developed the concept for the paper and agreed to an outline. Author 1 drafted the first version of the paper. All authors contributed to substantial sections to the paper. All authors made substantial revisions to the paper. All authors have agreed to the final version. Acknowledgements: We are most grateful to students and doctors who shared their time and experiences with us. We also thank Professor Ericka Johnson, leader of this research project. Funding: This work was supported by the Swedish Research Council.

Conflicts of interest: none.

Ethical approval: This study was approved by the research ethics board at Linköping University.

\section{REFERENCES}

${ }^{1}$ Shapiro S. Degrees of freedom: The interaction of standards of practice and engineering judgment. Sci Technol Human Values 1997;22 (3):286-316.

${ }^{2}$ Hochschild AR. Emotion work, feeling rules, and social structure. AJS 1979;85 (3):551-575. 
${ }^{3}$ Lindberg O. Undergraduate socialization in medical education: ideals of professional physicians' practice. Learn Health Soc Care 2009;2 (4):181-190.

${ }^{4}$ See Lave J, Wenger E. Situated learning: Legitimate peripheral participation. Cambridge:

Cambridge University Press; 1991.

${ }^{5}$ Thoits PA. Emotion norms, emotion work, and social order. In: Manstead SR, Frijda N, Fischer

A, eds. Feelings and emotions. Cambridge: Cambridge University Press; 2004: 359-378.

${ }^{6}$ Leavitt J. Meaning and feeling in the anthropology of emotions. Am Ethnol 1996;23 (3):514-539.

${ }^{7}$ Cottingham MD, Erickson RJ. The Promise of Emotion Practice: At the Bedside and Beyond.

Work Occup 2019;0 1-27.

${ }^{8}$ Ker JS. Developing professional clinical skills for practice - the results of a feasibility study using a reflective approach to intimate examination. Med Educ 2003;37 (1):34-41.

${ }^{9}$ Siwe K, Berterö C, Wijma B. Performing the First Pelvic Examination: Female Medical Students' Transition to Examiners. Patient Educ Couns 2007:69 (1-3):55-62.

${ }^{10}$ Robins LS, Alexander GL, Dicken LL, Belville WD, Zweifler AJ. The effect of a standardized patient instructor experience on students' anxiety and confidence levels performing the male genitorectal examination. Teach Learn Med 2009;9 (4):264-269.

${ }^{11}$ Siwe K, Berterö C, Wijma B. Unexpected enlightening of a "female world". Male medical students' experiences of learning and performing the first pelvic examination. Sex Reprod Health 2012;3 (3):123-127.

${ }^{12}$ Dakum NK, Ramyil VM, Agbo S, Ogwuche E, Makama BS, Kidmas AT. Digital rectal examination for prostate cancer: attitude and experience of final year medial students. Niger J Clin Pract 2007;10 (1):5-9. 
${ }^{13}$ Siebeck M, Schwald B, Frey C, Röding S, Stegmann K, Fischer F. Teaching the rectal examination with simulations: effects on knowledge acquisition and inhibition. Med Educ 2001;45 (10):1025-1031.

${ }^{14}$ Smith P, Choudhury S, Clark JT. The effectiveness of gynaecological teaching associates in teaching pelvic examination: a systematic review and meta-analysis. Med Educ 2015;49 (12):1197-1206.

${ }^{15}$ Jha V, Al-Hity A, Quinton ND. Patient involvement in teaching and assessing. Med Educ 2010;44 (4):347-57.

${ }^{16}$ Bolier M, Doulougeri K, de Vries J, Helmich E 'You put up a certain attitude': a 6-year qualitative study of emotional socialization. Med Educ 2018;52 (10):1041-1051.

${ }^{17}$ Gillespie H, Kelly M, Gormley G, King N, Gilliland D, Dornan T. How can tomorrow's doctors be more caring? A phenomenological investigation. Med Educ 2018;52 (10):1052-1063.

${ }^{18}$ Gleisner J. Prostataundersökningen och den (o)känslige mannen [The prostate exam and the (in)sensitive man]. In: Björkman M, ed. Prostatan - det ständiga gisslet [The prostate - a constant torment]. Lund: Nordic Academic Press; 2018:43-58.

${ }^{19}$ Hunter SA, McLachlan A, Ikeda T, Harrison MJ, Galletly DC. Teaching of the sensitive examinations: An international survey. J Prev Med 2014;4 (1):41-49.

${ }^{20}$ Sörensdotter R, Siwe K. Touching the private parts: how gender and sexuality norms affect medical students’ first pelvic examination. Cult Health Sex 2016:18 (11):1295-1308.

${ }^{21}$ Underman K. 'It's the knowledge that puts you in control'. Gend Society 2011;25 (4):431-450.

${ }^{22}$ Barrows H, Tamblyn R. Problem-based learning: An approach to medical education. Springer Series on Med Educ No. 1. NY: Springer Publishing; 1980.

This article is protected by copyright. All rights reserved 
${ }^{23}$ Cf. Gleisner J. Negotiating the normal birth. Norms and emotions in midwifery education.

Linköping: Linköping studies in arts and sciences; 2013.

${ }^{24}$ Emerson RM, Fretz RI, Shaw LL. Writing Ethnographic Fieldnotes. Chicago and London: The

University of Chicago Press $2^{\text {nd }}$ edition; [1995] 2011.

${ }^{25}$ Agar MH. The Professional Stranger. An informal introduction to ethnography. San Diego, CA:

California Academic Press; 1996.

${ }^{26}$ Zembylas M. Theory and methodology in researching emotions in education. Int $J$ Res Meth

Educ 2007;30 (1):57-72.

${ }^{27}$ Cf. Geertz C. The interpretation of cultures. New York: Basic Books 1973.

${ }^{28}$ Sturdy A. Knowing the unknowable? A discussion of methodological and theoretical issues in emotion research and organizational studies. Organization 2003;10 (10):81-105.

${ }^{29}$ Good Research Practice. Swedish Research Council. Stockholm. 2014-10-05 [2011]; 2017.

${ }^{30}$ Siwe K. Learning the Pelvic Examination. Linköping: Linköping University Medical

Dissertations ISSN 0345-0082; 1031; 2007.

${ }^{31}$ Siwe K. Learning the Pelvic Examination. DVD. A guide to teaching and learning. Vreta Kloster, Sweden: Media Center TVB AB; 2013.

32 Damber JE, Peeker R. editors. Urologi [Urology]. Lund: Studentlitteratur $2^{\text {nd }}$ edition; [2006] 2012.

${ }^{33}$ Damber JE, Peeker R. editors. Urologi [Urology]. Lund: Studentlitteratur $2^{\text {nd }}$ edition; [2006] 2012:320.

${ }^{34}$ Gillespie H, Kelly M, Gormley G, King N, Gilliland D, Dornan T. How can tomorrow's doctors be more caring? A phenomenological investigation. Med Educ 2018;52 (10):1052-1063. 
${ }^{35}$ Hochschild AR. The managed heart: commercialization of human feeling. Berkeley and Los Angeles, CA: University of California Press; [1983] 2012.

${ }^{36}$ Siwe K, Wijma K, Stjernquist M, Wijma B. Medical students learning the pelvic examination: Comparison of outcome in terms of skills between a professional patient and a clinical patient model. Patient Educ Counc 2007;68 (3):211-217.

${ }^{37}$ Hilden M, Sidenius K, Langhoff-Roos J, Wijma B, Schei B. Women's experiences of the gynecologic examination: factors associated with discomfort. Acta Obstet Gynecol Scand 2003;82 (11):1030-1036.

${ }^{38}$ Gleisner J. Prostataundersökningen och den (o)känslige mannen [The prostate exam and the (in)sensitive man]. In: Björkman M, ed. Prostatan - det ständiga gisslet [The prostate - a constant torment]. Lund: Nordic Academic Press; 2018:43-58.

${ }^{39}$ Siwe K, Berterö C, Wijma B. Performing the First Pelvic Examination: Female Medical Students' Transition to Examiners. Patient Educ Couns 2007:69 (1-3):55-62.

${ }^{40}$ Damber JE, Peeker R. editors. Urologi [Urology]. Lund: Studentlitteratur $2^{\text {nd }}$ edition; [2006] 2012:320.

${ }^{41}$ Patulny R, Smith V, Soh K. Generalising men's affective experiences. Norma 2017;12 (34):220-239.

${ }^{42}$ Robins LS, Alexander GL, Dicken LL, Belville WD, Zweifler AJ. The effect of a standardized patient instructor experience on students' anxiety and confidence levels performing the male genitorectal examination. Teach Learn Med 2009;9 (4):264-269.

${ }^{43}$ Lindberg O. Undergraduate socialization in medical education: ideals of professional physicians' practice. Learn Health Soc Care 2009;2 (4):181-190. 
${ }^{44}$ Coldicott Y, Pope C, Roberts C. The ethics of intimate examinations - teaching tomorrow's doctors. BMJ 2003;326 (7380):97-99. 